\title{
Two distinct HLA-DR3 haplotypes are associated with age related heterogeneity in Type 1 (insulin-dependent) diabetes
}

\author{
I. Deschamps ${ }^{1}$, A. Marcelli-Barge ${ }^{2}$, J.C. Poirier ${ }^{2}$, O.Cohen-Haguenauer ${ }^{3}$, H. Abderrahim ${ }^{4}$, D.Cohen ${ }^{4}$, \\ H. Lestradet ${ }^{1}$ and J.Hors ${ }^{3}$ \\ ${ }^{1}$ INSERM U. 290, Hôpital Hérold, ${ }^{2}$ Laboratoire d'Immunologie et d'Histocompatibilité, ${ }^{3}$ INSERM U.93, Hôpital St Louis, and \\ ${ }^{4}$ Centre d'Etudes du Polymorphisme Humain, Paris, France
}

\begin{abstract}
Summary. Heterogeneity between two haplotypes in linkage disequilibrium with DR3: B8, C4AQOB1,BfS,DR3 and $\mathrm{B} 18, \mathrm{C} 4 \mathrm{~A} 3 \mathrm{BQO}, \mathrm{BfF} 1, \mathrm{DR} 3$, with regard to age at onset of Type 1 (insulin-dependent) diabetes mellitus, was investigated in 325 unrelated French patients (146 males and 179 females, age at onset 1 month to 29 years) who were genotyped for HLA-A, B, C, DR and Bf and 225 of whom were typed for the C4A, B complement components. A subgroup of 82 patients and 75 control subjects were tested for DR $\beta$ and DQ $\beta$ DNA restriction fragment length polymorphism. The distribution according to age at onset and the mean ages at onset were compared between patients bearing B8, DR3 $(n=58)$, B18,DR3 $(n=62)$ or other DR3 haplotypes (Bx, DR3, $n=70$ ), the haplotype segments C4AQOB1,DR3 $(n=41)$ or C4A3BQO,DR3 $(n=52)$ and the $\mathrm{C} 4$ null alleles C4AQO $(N=48)$ or C4BQO $(n=112)$ alone. The B8,DR3 haplotype, its smaller segment $\mathrm{C} 4 \mathrm{AQOB} 1, \mathrm{DR} 3$ or $\mathrm{C} 4 \mathrm{AQO}$ alone were associated with age at onset after 6 years $(p<0.01,<0.08$ and $<0.02$ respectively); on the other hand, the B18,DR3 haplotype, its segment $\mathrm{C} 4 \mathrm{~A} 3 \mathrm{BQO}, \mathrm{DR} 3$ or $\mathrm{C} 4 \mathrm{BQO}$ alone were significantly more frequent in patients aged less than 6 years at onset ( $p<0.02,<0.01$ and $<0.01$ respectively). Accordingly, the mean age of onset was significantly lower in the latter
\end{abstract}

compared with the former patiens $(p<0.02,<0.02$ and $<0.01$ respectively). No age-related variation was observed in BX,DR3 patients and their mean age of onset was intermediate. The observed age distributions were sex dependent: that of C4AQO was mainly observed in males, that of C4BQO in females. Restriction fragment length polymorphism analysis in 37 patients and 32 control subjects positive for DR3 showed distinct patterns which correlated with DR3 and/or DQW2 borne by the $\mathrm{B} 8(n=11)$ and the B18 $(n=18)$ haplotypes, respectively. BX,DR3 subjects exhibited either one or the other of these patterns. In the patients, the B18 associated fragments were found in most cases; whereas the B8 associated pattern was more frequent in the control subjects. These results provide evidence that a heterogeneous genetic background associated with two subsets of DR3 and/or silent alleles of the fourth component of complement could account for differences in the clinical expression of Type 1 diabetes.

Key words: Type 1 (insulin-dependent) diabetes, HLA-types, heterogeneity, age at onset, sex, genetic susceptibility, extended haplotypes, $\mathrm{C} 4, \mathrm{Bf}$ complement components - DR $\beta$, $D Q \beta$, DNA polymorphism, restriction fragment length polymorphism.
It is still a controversial issue whether genetical heterogeneity in Type 1 (insulin-dependent) diabetes mellitus may be defined on the basis of various clinical characteristics associated with different markers of susceptibility [1]. Several studies have involved the age of onset of the disease, yielding conflicting results [2-8]. The most widely confirmed association is that of early onset with the properdin factor B allele BfF1 [9-12]. In a previous study [13], we also have found a strong association with HLA-B18 but not with the B18,BfF1,DR3 haplotype, possibly because of the small sample size.

DR3 and DR4 have been reported to be associated with age at onset before 20 or 30 years $[14,15]$, and in one study DW3 and DW4 were associated with onset that occurred before the age of 3 years [16]. No agerelated associations have been described for DR3; however, no study so far has taken into account the heterogeneity of this serologically defined specificity. Indeed, two subsets of DR3, in linkage disequilibrium with the extended haplotpyes A1,B8,C4AQOB1,BfS and $\mathrm{AW} 30, \mathrm{~B} 18, \mathrm{C} 4 \mathrm{~A} 3 \mathrm{BQO}, \mathrm{BfF} 1$, respectively, have been recently shown to differ with respect to $D R \beta$ and $D Q \beta$ DNA restriction fragment length polymorphisms in healthy subjects [17].

The biological significance of these haplotypes is still debated [18]. There is strong evidence that Type 1 
diabetes is primarily associated with class II antigens, the association with other alleles borne by these haplotypes being secondary to linkage disequilibrium. Nevertheless, as long as it is not known which are the exact molecules involved in the susceptibility, the implication of products encoded by the other alleles of these haplotypes cannot be excluded. Namely, the null alleles at the C4A and B loci, C4AQO and C4BQO, could by themselves be implicated in the pathogenesis of Type 1 diabetes and other autoimmune diseases. A deficiency of these complement proteins, important for immune cytolysis of virus infected cells and for clearance of immune complexes, could favour triggering events and in this way influence the onset of the disease.

In order to clarify these questions, we have studied a large group of juvenile - onset patients genotyped for 7 loci of the HLA complex, including the complement factors $\mathrm{Bf}, \mathrm{C} 4 \mathrm{~A}$ and $\mathrm{C} 4 \mathrm{~B}$, some of them investigated at the DR $\beta$ and DQ $\beta$ DNA level, and we found heterogeneity between subsets of patients carrying the two DR3 haplotypes and between patients carrying C4A and $\mathrm{C} 4 \mathrm{~B}$ null alleles.

\section{Subjects and methods}

A group of 325 unrelated French Type 1 diabetic patients, 146 males and 179 females, ages at onset ranging from 1 month to 29 years (mean 9.1 years) were studied. The patients were Caucasians, living in the Paris area but originating from all parts of France. They have been consecutively ascertained since 1978 at the paediatric diabetic center of the Herold Hospital (Paris). One hundred thirty-three patients previously reported [13] have been included in this study.

All patients and their families were genotyped for HLA-A, B, C, $\mathrm{DR}$ and $\mathrm{Bf}$ as previously described [19]; 225 patients were typed for the complement factor $\mathrm{C} 4 \mathrm{~A}$ and $\mathrm{C} 4 \mathrm{~B}$ alleles following the technique of Awdeh and Alper, as described [20, 21]. Haplotypes were unambiguously deduced in almost all cases. Two index cases in whom haplotypes could not be assigned because the parents shared the DR antigens were excluded. Further, in six cases homozygosity at the DR locus could not be confirmed due to the homozygosity of a parent; they were treated as true homozygotes. A total of 192 patients ( 88 males, 104 females) were DR3 positive. Among these, the relationship between different DR3 haplotypes and the age of onset of diabetes was analysed.

Besides B8 and B18, associated with the complotypes BfS,C4AQOB1 and BfF1,C4A3BQO, respectively, no HLA-B antigens or complement factors showed significant linkage disequilibrium with DR3 [18]. Thus, we considered three groups of patients according to the kind of DR3 haplotype they possessed: $a=B 8, D R 3$ $(n=58), \mathrm{b}=\mathrm{B} 18, \mathrm{DR} 3(n=62), \mathrm{c}=\mathrm{Bx}, \mathrm{DR} 3$ (neither $\mathrm{B} 8$ nor $\mathrm{B} 18$, $n=70$ ). Two patients bearing both a B8,DR3 and a B18,DR3 haplotype were excluded from the analysis. Another 13 DR3 homozygous patients were included in group a (2 patients $\mathrm{B} 8 / \mathrm{B} 8,2$ patients $\mathrm{B} 8 / \mathrm{BX})$, in group $\mathrm{b}(1$ patient $\mathrm{B} 18 / \mathrm{B} 18,3$ patients $\mathrm{B} 18 / \mathrm{BX})$ or in group c (5 patients $\mathrm{BX} / \mathrm{BX}$ ).

In order to assess the respective contributions of the extended haplotypes, on the one hand, of the silent complement alleles either in association with or independently of DR3, on the other, we compared patients carrying the haplotype segments BfS, C4AQOB1,DR3 and BfF1,C4A3BQO,DR3 (referred to as C4AQO,DR3 and C4BQO,DR3) without considering the HLA-B alleles; indeed, these segments show as strong linkage disequilibrium with DR3 as the whole extended haplotype but stronger association with the disease (at least C4BQO,DR3) [18].

We finally analysed the $\mathrm{C} 4 \mathrm{AQO}$ and $\mathrm{C} 4 \mathrm{BQO}$ alleles alone without taking into consideration HLA-B or DR alleles. Age-related associations were studied comparing the distribution of these haplotypes or complement factors according to four age-at-onset groups: Group I: 0-5 years, group II: $6-10$ years, group III: $11-15$ years, group IV: $>15$ years. Due to the predominantly paediatric recruitment in our hospital, the group of patients aged over 15 years at onset was very small (18 patients only). In addition, the mean ages at onset within each of the haplotype groups were compared. A sub-group of $82 \mathrm{pa}-$ tients was investigated for DNA restriction fragment length polymorphism (RFLP) using the Southern blot technique, as described elsewhere [22]. Digestions were carried out with four restriction enzymes (Eco RV, Hind III, Bam HI, Taq I) and hybridisations were performed with DR $\beta$ and DQ $\beta$ cDNA probes. The patients had been randomly selected among the whole patient group for their different DR allelic combinations and not for their particular haplotypes.

Among the 37 DR3 positive patients, the patterns were analysed comparing those who possessed the whole or part of the B8,DR3 haplotype ( $n=11)$, the whole or part of the B18,DR3 haplotype $(n=18)$ or other DR3 haplotypes (BX,DR3, $n=8$ ).

The distribution of age and sex in these groups was comparable to that in the larger groups analysed for the age associations. Seventy five healthy control subjects matched essentially for DR specificities were studied in the same way. There were 32 DR 3 positive subjects. However, as only four of them possessed a B8 haplotype and one a B18 haplotype, the comparison with the patients' haplotype groups was not possible. Therefore, the comparison between patients and control subjects was carried out pooling all DR3 positive subjects.

\section{Statistical analysis}

Distributions of haplotypes and complement factors were compared using chi square tests and Yates corrections when required. Mean ages of onset were expressed as mean \pm standard error of the mean (SEM) and statistical significance was calculated using Student's t-test.

\section{Results}

The distribution of patients according to sex, age at onset and HLA-DR types is presented in Table 1. No single DR allele or allelic combination showed any significant variation depending on the age of onset of diabetes or sex (not shown).

Table 2 shows the distribution according to age at onset of the B8,DR3, the B18,DR3 and other (BX,DR3) haplotypes. The distribution of the haplotype segments C4AQO,DR3 and C4BQO,DR3 and of the C4AQO and $\mathrm{C} 4 \mathrm{BQO}$ alleles alone is also given.

The B8,DR3 haplotype was significantly less frequent in children who developed diabetes before 6 years, compared with older children $(p<0.01)$. The C4AQO,DR3 haplotype segment and C4AQO alone showed very similar distributions as that of B8,DR3, although the age difference was not statistically significant for C4AQO,DR3. Note that the C4AQO allele occurred almost exclusively in association with DR3.

On the other hand, the B18, DR3 haplotype was significantly associated with younger age at onset $(p<0.02,<0.01$ and $<0.01$ for B18,DR3; C4BQO, DR3 and C4BQO respectively). It can be noted that 
Table 1. Distribution of patients according to sex, age at onset and HLA-DR types

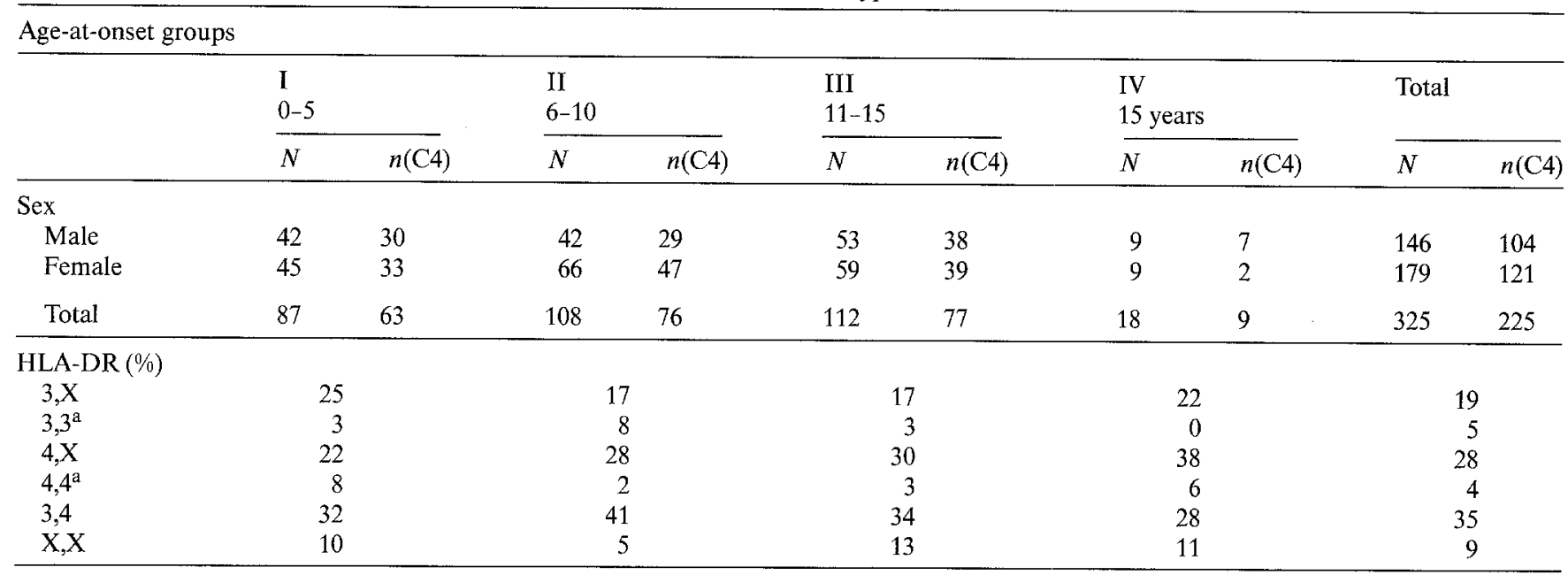

$N=$ Total number; $n(\mathrm{C} 4)=$ number $\mathrm{C} 4$ typed; X Designs DR antigens other than 3 or $4 ;{ }^{\text {a }}$ Including probable homozygosity: $3 / 3$ or-, $4 / 4$ or-

Table 2. Distribution of DR3 haplotypes and C4 null alleles in patients according to age at onset

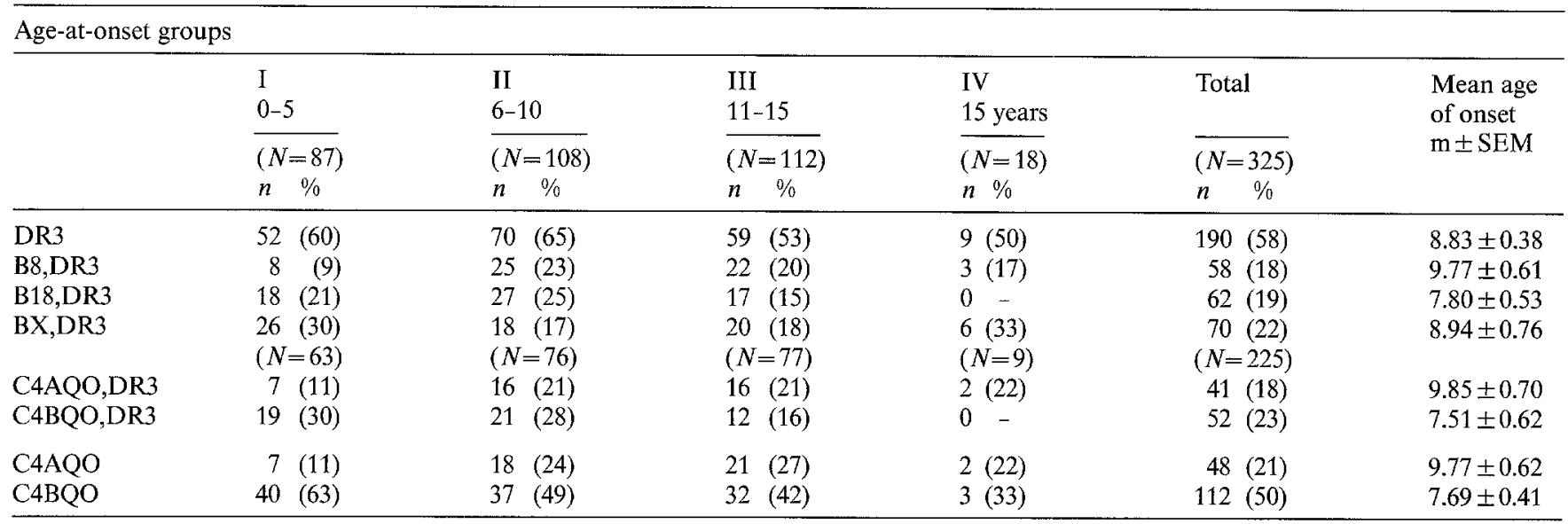

B8,DR3; C4AQO,DR3 and C4AQO: group I vs II + III + IV $p<0.01,<0.08$ and $<0.02$ respectively; B18,DR3 and C4BQO,DR3 groups I + II vs III + IV $p<0.02$ and $<0.01$ respectively; C4BQO: group I vs II vs III vs IV and group I vs groups II + III + IV $p<0.01$. Mean age of onset: $\mathrm{B} 8, \mathrm{DR} 3$ vs B18,DR3 and C4AQO,DR3 vs C4BQO,DR3: $p<0.02 ; \mathrm{C} 4 \mathrm{AQO}$ vs C4BQO: $p<0.01$

none of the patients who developed diabetes after age 15 years possessed either B18,DR3 or C4BQO,DR3.

The C4BQO allele was observed in the patients at the same frequency in the presence as in the absence of DR3. Associated or not with DR3, its frequency was highest among the youngest children $(63 \%)$ and decreased gradually with the age of onset (33\% among the patients aged over 15 years, $p<0.01$, Fig. 1 and Table 2).

BX,DR3 haplotypes did not show any significant age related distribution. The mean ages at onset were significantly lower in the patient groups bearing C4BQO, C4BQO,DR3 or B18,DR3 compared with C4AQO, C4AQO,DR3 or B8,DR3 positive ones $(p<0.01,<0.02$ and $<0.02$ respectively). The mean age of onset of BX,DR3 patients, was intermediate between that of B8 and B18 positive patients. In DR3 homozygous patients, the mean age of onset $(8.0 \pm 1.01$ years) was slightly, but not significantly lower than that in DR3 heterozygous subjects $(8.9 \pm 0.39$ years $)$ and so was that of 17 C4BQO homozygous patients (7.35 \pm 1.06 years) compared with that in C4BQO heterozygous ones ( $7.75 \pm 0.45$ years).

The associations between the B8 and B18 haplotypes or $\mathrm{C} 4$ null alleles and age showed sex-dependent differences, as illustrated in Figure 1, although the results have to be considered with caution due to the multiple comparisons carried out. Because of small sample size, groupe IV was excluded from this comparison. Significantly more boys were $C 4 A Q O$ positive compared with the girls among the children older than 6 years at onset $(p<0.01)$, and the association of C4AQO with age at onset was only observed in boys (10\% in the $0-5$ years old boys versus $36 \%$ in the older ones, $p<0.006$; non-significant in girls). The same sexrelated distribution was found for B8,DR3 and C4AQO,DR3 $(p<0.002$ and $<0.02$, respectively, for boys aged $0-5$ years versus $<6$ years, non-significant in girls; data not shown). 
Table 3. DR $\beta$ and DQ $\beta$ restriction fragment length polymorphism patterns in patients and control subjects bearing DR3 haplotypes

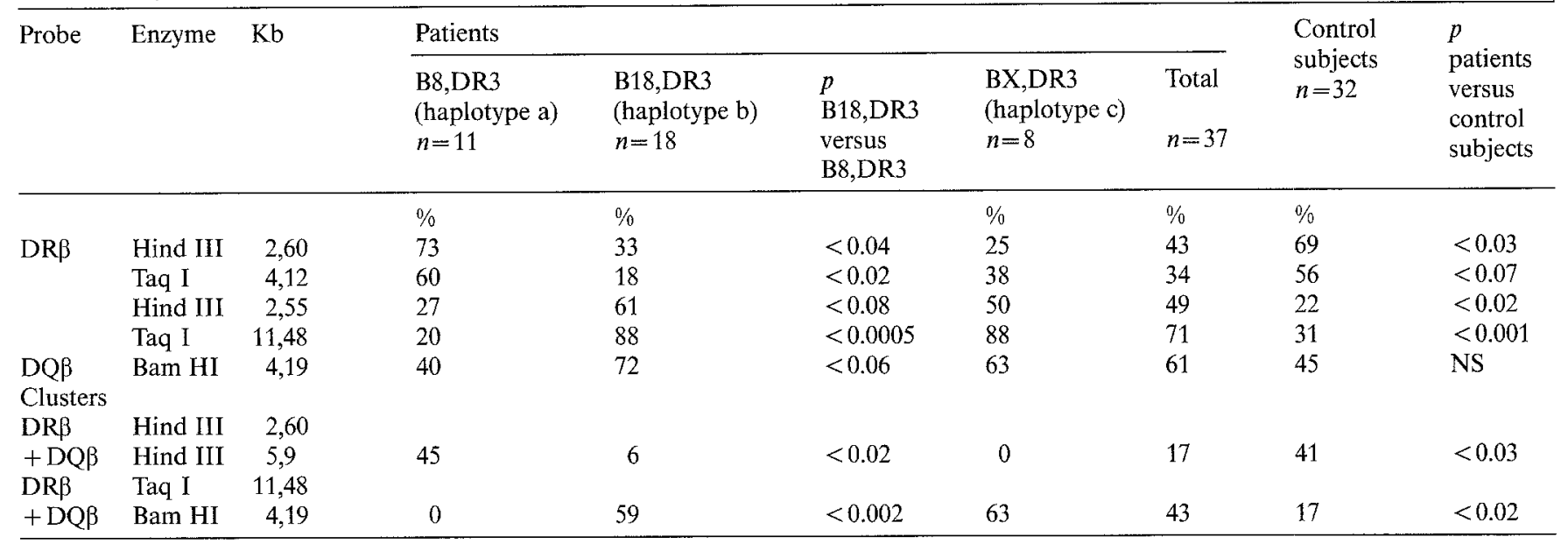

C $4 A Q 0$
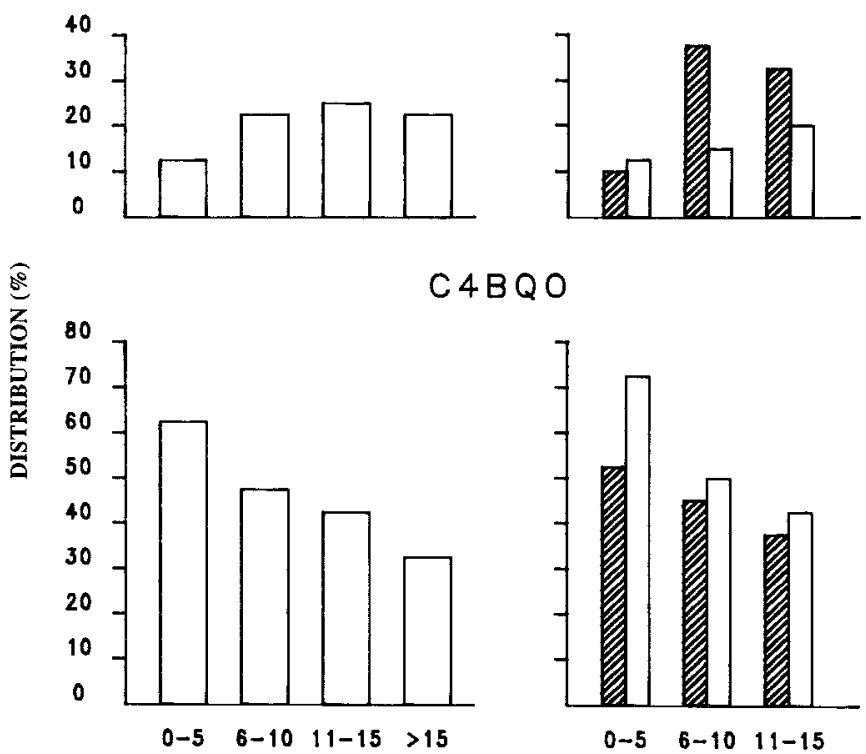

C $4 B Q 0$

AGE AT ONSET OF DIABETES

(YEARS)

Fig. 1. Distribution (\%) of the silent complement factor alleles C4AQO (upper panel) and C4BQO (lower panel) in Type 1 (insulindependent) diabetic patients according to age at onset. Left panel: all patients; C4AQO: group 0-5 years vs others, $p<0.02$; C4BQO: $p<0.01$ for comparison between the four groups or for groups $0-5$ years versus others. Right panel: distribution according to age at onset and sex; $\square=$ males; $\square=$ females. C4AQO: males $0-5$ years vs other males, $p<0.006$; males 6-15 years vs females, $p<0.01$. C4BQO: females $0-5$ years versus other females, $p<0.015$

Conversely, female patients more often carried C4BQO or C4BQO,DR3 haplotypes, although the difference was not significant. However, the age-relationship with this allele was more pronounced in females ( $73 \%$ of the $0-5$ years old girls carried C4BQO versus $47 \%$ of the older ones, $p<0.015$; non-significant in males).

The influence of female sex on the association between early onset and C4BQO was observed particularly in the case of C4BQO- non DR3 (45\% in the girls with onset before 6 years versus $22 \%$ in older ones, $p<0.01$ ). The mean ages of onset were not significantly different between males and females in these haplotype groups, possibly because of small sample size.

RFLPs of DR $\beta$ and DQ $\beta$ genes in DR3 positive patients showed two distinct patterns which correlated with B8,DR3 and B18,DR3 (haplotypes a and b, respectively). Table 3 shows several fragments and groups of fragments (clusters) which differed between the two groups of patients and which did not correlate with any serologically defined specificity other than DR3, DRW 52 or DQW2. Particularly, a DR $\beta$ Taq I $11.48 \mathrm{~kb}$ fragment was found in $88 \%$ of patients carrying the haplotype b but only in $20 \%$ of patients with haplotype a $(p<0.001)$.

Two DR $\beta$ fragments (Hind III $2.60 \mathrm{~kb}$ and Taq I $4.12 \mathrm{~kb}$ ) were increased in haplotype a compared with haplotype $b$ positive patients $(p<0.04$ and $<0.02$ respectively). In each group of patients, a cluster composed of a DR $\beta$ and a DQ $\beta$ fragment was present in about half of the subjects while decreased or absent in the other group $(p<0.02$ and $<0.002)$.

One patient was B18,DR3 homozygous; he possessed the cluster associated with haplotype $b$ and none of the fragments associated with hyplotype a. Another patient was B8,DR3/B5,DR3 and carried the cluster associated with haplotype a, together with the Taq I $11.48 \mathrm{~kb}$ fragment. There was no pattern characteristic of patients bearing non-B8, non-B18 (non-C4AQO, non-C4BQO) DR3 haplotypes, most of whom exhibited the pattern encountered in the $b$ haplotype group ( $7 / 8 \mathrm{Bx}, \mathrm{DR} 3$ patients possessed the DR $\beta$ Taq I $11.48 \mathrm{~kg}$ band and only $3 / 8$ the $4.12 \mathrm{~kb}$ band). Among the control subjects, the frequencies of these patterns differed from those among the patients. The small number of B8 and B18 positive patients did not allow comparisons between individual haplotype groups. However, the subject who carried B18,DR3 possessed the pattern associated with haplotype $b$ and two out of the four B8 positive subjects possessed the pattern associated with haplotype a. 
On the whole, the fragments and clusters associated with haplotype a were observed in the control subjects at greater frequencies and those associated with haplotype $b$ at lower frequencies compared with the diabetic group (Table 3). Statistical significant differences between patients and control subjects were found for the presence of three DR $\beta$ fragments: Hind III $2.60 \mathrm{~kb}$, Hind III $2.55 \mathrm{~kb}$ and Taq I $11.48 \mathrm{~kb}(p<0.03,<0.02$ and $<0.001$ respectively) and two clusters: $D R \beta$ Hind III $2.60 \mathrm{~kb}+\mathrm{DQ} \beta$ Hind III $5.9 \mathrm{~kb}(p<0.03)$ and DR $\beta$ Taq I $11.48 \mathrm{~kg}+\mathrm{DR} \beta$ Bam HI $4.19 \mathrm{~kb}(p<0.01)$.

Four control subjects were DR3 homozygous. In one B8/B27 positive individual, fragments associated with both $\mathrm{a}$ and $\mathrm{b}$ haplotypes were found. The other three subjects exhibited only patterns characteristic of haplotype a.

\section{Discussion}

This study brings some evidence that not only the $\mathrm{B} 18, \mathrm{BfF} 1$ haplotype, as suggested in previous studies [9-13], but also the silent complement factor allele C4BQO by itself characterise a particularly early-onset form of Type 1 diabetes occurring mostly before 6 years of age. Conversely, the B8, DR3 haplotype has been observed to occur more often in patients older than 6 years at onset.

The age of onset is of importance in the search for heterogeneity since it may reflect different aetiological mechanisms in patients, including age dependent viral susceptibility, according to different genetical background of immune responsiveness. Although DR3 as an entity has been reported to be independent of age at onset [15], indirect evidence has suggested its heterogeneity. On the one hand, BfF1 and B18 are in linkage disequilibrium with DR3 $[18,23]$ - a haplotype more common in patients of Mediterranean than of Northern European origin [11]; on the other hand, the B8,DR3 haplotype has been found increased in diabetic patients with associated autoimmune manifestations who usually develop the disease after 30 years of age $[24,25]$.

Differences between B8,DR3 and B18,DR3 haplotypes with respect to $D R \beta$ and $D Q \beta$ restriction fragment length polymorphism have suggested a molecular basis for such heterogeneity, at least in the normal population studied [17]. In our study of a large sample of Type 1 diabetic patients from a homogeneous population in whom these two haplotypes occur at approximately equal frequencies, we were able to demonstrate that the age-related clinical heterogeneity associated with each haplotype correlated with heterogeneity at the DNA level. Patients and control subjects with nonB8, non-B18,DR3 haplotypes exhibited one or the other of these DR3 subsets. Interestingly enough, however, the majority of the patients possessed the pattern characteristic of the B18 haplotype which was decreased in the control subjects. This finding suggests a major role for this particular class II subset in diabetes, in accordance with the fact that the B18,DR3 haplotype, at least in the French population, shows much stronger association with the disease than the B8,DR3 haplotype [18]. If this particular DR3 molecule or a product of an associated allele had some direct influence on the age of onset, then the age of onset in BX,DR3 patients would be expected to be in accordance with the DR subtype. In our study, the number of these patients investigated for RFLP was not large enough to examine the correlation between the individual patterns and age of onset. This must be confirmed in larger studies, including in those populations in whom the B18,DR3 haplotype is infrequent in diabetes.

At present, the question remains open which are the respective roles played by the class II products, the haplotypes in linkage disequilibrium or the complement factors, in the specific immune responses and their interactions with environmental and hormonal factors which could favour an earlier onset of the disease. Among them sex-related influences could be common; and, in fact, such variations have already been reported $[7,16]$, even though the nature and the mechanism of eventual sex related factors remain unknown.

A direct involvement of the $\mathrm{C} 4$ null alleles, mainly C4BQO, has been suggested by their role in immune defense. Charlesworth et al. [26] have recently demonstrated in young diabetic patients reduced serum levels of several complement proteins which partially, although not exclusively, depended on the presence of null alleles. This observation and our data which associate $\mathrm{C} 4 \mathrm{BQO}$ by itself with young age of onset are in accordance with the hypothesis of a relationship between diminished protection against viruses due to a defective complement mechanism and early-onset diabetes, raised already several years ago [27]. The report on a 16-month old child [28] who suffered from an acute Coxsackie B5 virus infection of the pancreas contemporaneous with onset of diabetes and who was homozygous for BfF1,C4BQO may illustrate the potential importance of such a mechanism, at least in some cases.

Alternatively, $\mathrm{C} 4$ proteins may be involved in immune clearance mechanisms and in this way contribute to the pathogenesis of Type 1 diabetes as of other autoimmune disorders characterised by $\mathrm{C} 4 \mathrm{~A}$ and/or $\mathrm{C} 4 \mathrm{~B}$ null alleles $[29,30]$.

Acknowledgements. We are indebted to H. Bleux for preparation of the manuscript. This work was supported by INSERM, CNAM (N ${ }^{\circ}$ 62789 411, MRI (No 83Co284) CRAMIF (1985) and the Aide aux Jeunes Diabétiques.

\section{References}

1. Rotter JI, Rimoin DL (1979) Diabetes mellitus: the search for genetic markers. Diabetes Care 2: 215-226

2. Illeni MT, Pellegris G, Del Guercio MJ, Tarantino A, Busetto F, Di Pietro C, Clerici E, Ganotta Gl, Chiumello G (1977) HLA antigens in diabetic children. Diabetes 26:870-873 
3. Christy M, Green A, Christau B, Kromann H, Nerup J, Platz P, Thomsen M, Ryder L, Svejgaard A (1979) Studies of the HLASystem and insulin-dependent diabetes mellitus. Diabetes Care 2: 209-214

4. Shernthaner G, Ludwig H, Mayr WR (1976) Juvenile diabetes mellitus: HLA antigen frequencies dependent on the age of onset of the disease. J Immunogenet 3: 117-121

5. Cudworth AG, Woodrow JC (1976) Genetic susceptibility in diabetes mellitus: analysis of the HLA-associations. Br Med J 2: 846

6. Barbosa J, Bach FH, Rich SS (1982) Genetic heterogeneity of diabetes and HLA. Clin Genet 21: 25-32

7. Eberhardt MS, Wagener DK, Orchard TJ, Laporte RE, Cavender DE, Rabin BS, Atchinson RW, Kuller LH, Drash AL, Becker DJ (1985) HLA heterogeneity of insulin-dependent diabetes mellitus at diagnosis. The Pittsburgh IDDM study. Diabetes 34: 1247-1252

8. Ludvigsson J, Samuelsson U, Beauforts C, Deschamps I, Dorchy H, Drash A, François R, Herz G, New M, Schober E (1986) HLA-DR3 is associated with a more slowly progressive form of Type 1 (insulin-dependent) diabetes. Diabetologia 29: 207-210

9. Kirk RL, Serjeantson SW, Theophilus J, Zimmet P, Whitehouse S; Court JM (1979) Age relationship between insulindependent diabetes and rare alleles of properdin factor B-Lancet II: 537

10. Barbosa J, Weitkamp L, Guttormsen S, Johnson S, Szalapski E (1979) Bf in early-onset insulin-dependent diabetes. Lancet II: $1239-1240$

11. Cambon de Mouzon A, Ohayon E, Hauptmann G, Sevin A, Abbal M, Sommer E, Vergnes H, Ducos J (1982) HLA-A, B, C, $\mathrm{DR}$ antigens, Bf, C4 and Glyoxalase I (GLO) polymorphisms in french Basques with insulin-dependent diabetes mellitus. Tissue Antigens 19: 366-379

12. Bertrams J, Baur MP, Grüneklee D, Gries FA (1981) Age-related association of insulin-dependent diabetes mellitus with Bf F1 and the HLA-B18, Bf F1 haplotype. Diabetologia 21: 47-49

13. Deschamps I, Lestradet H, Goderel I, Marcelli-Barge A, Schmid M, Hors J (1983) Age-related heterogeneity of insulindependent diabetes mellitus. Diabete et Métabolisme 9: 259-263

14. Svejgaard A, Platz P, Ryder LP (1980) Insulin-dependent diabetes mellitus. Joint Report of the 8th International histocompatibility Workshop. In: Terasaki P (ed) Histocompatibility Testing. UCLA; Los Angeles, pp 638-656

15. Svejgaard A, Jakobsen BK, Platz P, Ryder LP, Nerup J, Christy M, Borch-Johnsen K, Parving HH, Deckert T, Molsted Pedersen L, Kühl C, Buschard K, Green A (1986) HLA associations in insulin-dependent diabetes: search for heterogeneity in different groups of patients from a homogeneous population. Tissue Antigens 28: 237-244

16. Mustonen A, Ilonen J, Tiilikainen A, Kataja M, Akerblom HK (1985) An analysis of epidemiological data in HLA-typed diabetic children. Diabetologia 28: 397-400

17. Wescott MZ, Awdeh ZL, Yunis EJ, Alper CA (1987) Molecular analysis distinguishes two HLA-DR3-bearing major histocompatibility complex extended haplotypes. Immunogenetics 26 : $370-374$
18. Deschamps I, Marcelli-Barge A, Lallemand N, Poirier JC, Bochu V, Prevost P, Busson A, Masset M, Lestradet H, Hors J (1988) Study of cis and trans interactions between extended HLA haplotypes in insulin-dependent diabetes. Tissue Antigens 31: 259-269

19. Deschamps I, Lestradet H, Bonaïti C, Schmid M, Busson M, Benajam A, Marcelli-Barge A, Hors J (1980) HLA-genotype studies in juvenile insulin-dependent diabetes. Diabetologia 19: 189-191

20. Awdeh ZL, Alper CA (1980) Inherited structural polymorphism of the fourth component of human complement. Proc Natl Acad Sci USA 77: 3576-3580

21. Marcelli-Barge A, Poirier JC, Schmid M, Deschamps I, Lestradet H, Prevost P, Hors J (1984) Genetic polymorphism of the fourth component of complement and Type 1 (insulin-dependent) diabetes. Diabetologia 27: 116-117

22. Cohen-Haguenauer O, Robbins E, Massart C, Busson M, Deschamps I, Hors J, Lalouel JM, Dausset J, Cohen D (1985) A systematic study of HLA class II $\beta$ DNA restriction fragments in insulin-dependent diabetes mellitus. Proc Natl Acad Sci USA 82: $3335-3339$

23. Contu L, Deschamps I, Lestradet H, Hors J, Schmidt M, Busson M, Benajam A, Marcelli-Barge A, Dausset J (1982) HLA-haplotype study of 53 juvenile insulin-dependent diabetic families. Tissue Antigens 20: 123-140

24. Farid NR, Larsen B, Payıe R, Noel EP, Simpson L (1980) Polyglandular autoimmune disease and HLA. Tissue Antigens 16: 23-29

25. Gony J, Vexiau P, Lhomme C, Marcelli A, Poirier JC, Bochu V, Cathelineau G, Assan R, Deschamps I, Hors J (1988) MHC Class I, II, III antigens study in 70 insulin-dependent diabetics with associated auto-immune diseases. Tissue Antigens 31 : 229-234

26. Charlesworth JA, Timmermans V, Golding J, Campbell LV, Peake PW, Pussell BA, Wakefield D, Howard N (1987) The complement system in Type 1 (insulin-dependent) diabetes. Diabetologia $30: 372-379$

27. Hauptmann G (1980) C4 deficiency in early-onset insulindependent diabetes: a hypothesis. Lancet I: 1034

28. Champsaur HF, Bottazzo GF, Bertrams J, Assan R, Bach C (1982) Virologic, immunologic and genetic factors in insulin de pendent diabetes mellitus. J Pediatr 100: 15-20

29. Vergani D, Wells L, Larcher VF, Nasaruddin BA, Davies ET, Mieli-Vergani G, Mowet AP (1985) Genetically determined low C4: a predisposing factor to auto-immune chronic active hepatitis. Lancet II: $294-298$

30. Rynes RI (1982) Inherited complement deficiency status and SLE. Clin Rheum Dis 8: 29-47

Received: 10 March 1988

and in revised form: 7 October 1988

Dr. I. Deschamps

Service Endocrinologie de l'Enfant et Diabète

Hôpital des Enfants-Malades

149 , rue de Sèvres

F-75015 Paris

France 